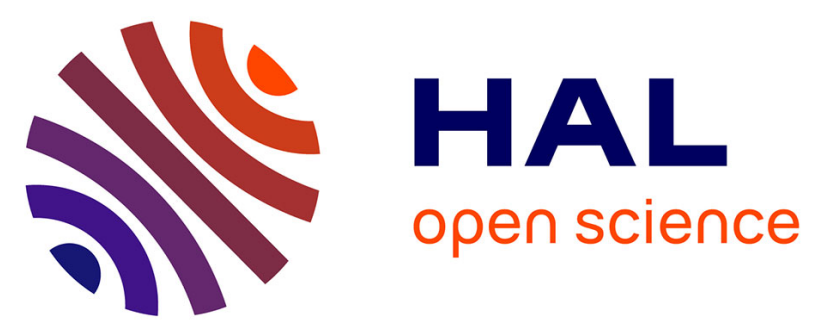

\title{
Nitro End Groups Remarkable Vibrational Reporters for Charge Transfer in the Excited States of Oligo(p-phenyleneethynylene)-Bridged Donor-Acceptor Dyads
}

J. Kubicki, Maciej Lorenc, P. Cochelin, O. Mongin, A. Amar, A. Boucekkine, A. Gaje, M.G. Humphrey, M. Morshedi, S. Lorenzen, et al.

\section{To cite this version:}

J. Kubicki, Maciej Lorenc, P. Cochelin, O. Mongin, A. Amar, et al.. Nitro End Groups Remarkable Vibrational Reporters for Charge Transfer in the Excited States of Oligo(p-phenyleneethynylene)Bridged Donor-Acceptor Dyads. Journal of Physical Chemistry C, 2020, 124 (18), pp.9755-9764. 10.1021/acs.jpcc.0c01532 . hal-02862821

\section{HAL Id: hal-02862821}

\section{https://hal-univ-rennes1.archives-ouvertes.fr/hal-02862821}

Submitted on 15 Jun 2020

HAL is a multi-disciplinary open access archive for the deposit and dissemination of scientific research documents, whether they are published or not. The documents may come from teaching and research institutions in France or abroad, or from public or private research centers.
L'archive ouverte pluridisciplinaire HAL, est destinée au dépôt et à la diffusion de documents scientifiques de niveau recherche, publiés ou non, émanant des établissements d'enseignement et de recherche français ou étrangers, des laboratoires publics ou privés. 


\title{
Nitro End-Groups: Remarkable Vibrational
}

\section{Reporters for Charge Transfer in the Excited States}

\section{of Oligo( $p$-Phenyleneethynylene)-Bridged Donor-}

\section{Acceptor Dyads}

\author{
Jacek Kubicki, ${ }^{,[a]}$ Maciej Lorenc, ${ }^{[b]}$ Pierre Cochelin, ${ }^{[a, b]}$ Olivier Mongin, ${ }^{[c]}$ Anissa Amar, ${ }^{[d]}$ \\ Abdou Boucekkine, ${ }^{[c]}$, Arnold Gaje, ${ }^{[a, b]}$ Mark G. Humphrey, ${ }^{[e]}$ Mahbod Morshedi, ${ }^{[e]}$ Sabine \\ Lorenzen, ${ }^{[f]}$ Florian Rauch, ${ }^{[f]}$ Charlotte Scheufler, $[f]$ Todd B. Marder[f] and Frédéric Paul ${ }^{*},[c]$
}

[a] Adam Mickiewicz University, Faculty of Physics, Uniwersytetu Poznańskiego 2, 61-614 Poznań, Poland, [b] Univ Rennes, CNRS, IPR (Institut de Physique de Rennes) - UMR 6251, F35000 Rennes, France, [c] Univ Rennes, CNRS, ISCR (Institut des Sciences Chimiques de Rennes) - UMR 6226, F-35000, Rennes, France, [d] Département de Chimie, Faculté des Sciences, Université Mouloud Mammeri, 15000 Tizi-Ouzou, and Faculté de Chimie, Université des Sciences et de la Technologie Houari-Boumediene, 16111 Bab-Ezzouar (Algeria). [e] Research School of Chemistry, Australian National University, Canberra, ACT 2601, Australia. [f] Institut für Anorganische Chemie and Institute for Sustainable Chemistry \& Catalysis with Boron (ICB), Julius-Maximilians-Universität Würzburg, Am Hubland, 97074 Würzburg (Germany). 


\title{
AUTHOR INFORMATION
}

\section{Corresponding Author}

*jacek.kubicki@amu.edu.pl, frederic.paul@univ-rennes1.fr

\begin{abstract}
The D- $\pi-\mathrm{A}$ dyads $\left[(n-\mathrm{Hex})_{2} \mathrm{~N}\left(1,4-\mathrm{C}_{6} \mathrm{H}_{4}\right)\right] \mathrm{C} \equiv \mathrm{C}\left[\left(1,4-\mathrm{C}_{6} \mathrm{H}_{4}\right) \mathrm{NO}_{2}\right] \quad(1)$ and $[(n-$ Hex $\left.)_{2} \mathrm{~N}\left(1,4-\mathrm{C}_{6} \mathrm{H}_{4}\right)\right] \mathrm{C} \equiv \mathrm{C}\left(1,4-\mathrm{C}_{6} \mathrm{H}_{4}\right) \mathrm{C} \equiv \mathrm{C}\left[\left(1,4-\mathrm{C}_{6} \mathrm{H}_{4}\right) \mathrm{NO}_{2}\right]$ (2) have been studied by ultrafast timeresolved infrared absorption spectroscopy. After excitation into their singlet charge-transfer $\left({ }^{1} \mathrm{CT}\right)$ state, a fast decay (ca. 6 ps for 1 and 1 ps for 2 ) of the initially populated singlet state into a ground state (major pathway) and a longer-lived excited state (possibly the triplet state) is observed. The nitro and alkyne groups were used as vibrational reporters to probe the changes induced by the charge-transfer process. For the first time, we confirm experimentally that these changes are consistent with expectations based on the traditional valence-bond representations of the CT states of these push-pull chromophores. An almost identical charge transfer takes place in the two dyads, despite different length $\pi$-bridges between the donor and acceptor groups. Complementary DFT calculations support the experimental assignments and have helped clarifying the photophysical behavior of $\mathbf{1}$ and 2 .
\end{abstract}




\section{Introduction.}

Donor-acceptor (D-A) dyads are very important chromophores that play a pivotal role in an increasing number of key societal applications ${ }^{1}$ such as solar light harvesting, ${ }^{2-4}$ molecular sensing, ${ }^{5}$ bioimaging, ${ }^{6}$ or ultrafast information treatment. ${ }^{7,8}$ Evaluation of their performance in each of these fields is crucial, and such a task often relies on a detailed knowledge of the donoracceptor charge-transfer state which usually constitutes the lowest allowed excited state of these compounds. ${ }^{1}$ While theoretical modelling of such excited states can nowadays be undertaken routinely, the exact degree of charge transfer (CT) between the donor and acceptor end-groups has remained elusive. ${ }^{9}$ Ultrafast transient vibrational spectroscopies can greatly facilitate the optimization of compounds ${ }^{10,11}$ because charge-transfer leads to changes in various bond strengths in the excited molecule. Monitoring vibrational modes after photo-excitation can therefore provide reliable experimental insight into the structural changes underlying the chargetransfer process. A ubiquitous class of dyads are those in which the donor and acceptor groups are separated by oligo(1,4-phenyleneethynylene)-containing bridges. This type of bridge is rigid, highly versatile from the synthetic perspective, and chemically very resistant. ${ }^{12-20}$ Furthermore, alkyne vibrations are found in a specific range in the infrared (IR) region (1900-2200 $\mathrm{cm}^{-1}$ ), so these can provide a convenient probe to monitor changes in the bridge, as recently shown by Vauthey and coworkers ${ }^{10}$ and others. ${ }^{21-23}$ Herein, we report our results on related nitroterminated dyads (Scheme 1), and show that the nitro group is a remarkable vibrational reporter on the acceptor side of the charge-transfer. The ground states (GSs) of such molecules typically exhibit two N-O stretching modes that are easily recognizable in their IR vibrational spectra, namely an antisymmetric stretch in the $1500-1600 \mathrm{~cm}^{-1}$ region and a symmetric stretch in the $1400-1300 \mathrm{~cm}^{-1}$ region. ${ }^{24}$ These vibrational modes are directly affected by any change in electron 
density at the nitro group and, as such, they should provide an indication of the amount of charge transferred to this group. Indeed, upon population of the CT state, the increase in electron density at the nitro group induces a weakening of the $\mathrm{N}-\mathrm{O}$ bonds, which results in red-shifts of both the antisymmetric and symmetric stretching modes. Importantly, because the nitro group is redoxactive, the magnitude of the vibrational changes induced by transfer of one electron to this group may be experimentally estimated by spectroelectrochemistry, by monitoring the specific vibrational $v(\mathrm{~N}=\mathrm{O})$ modes upon one-electron reduction. Based on existing literature, ${ }^{25-27}$ selected experiments reveal shifts to lower wavenumbers of ca. $280 \mathrm{~cm}^{-1}$ for the antisymmetric and symmetric stretching modes of nitrobenzene, upon one-electron reduction of the nitro group attached to a phenyl ring when these modes are modelled by DFT computations and tracked by projection analysis. ${ }^{28,29}$

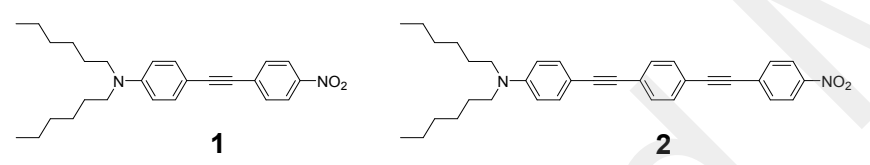

Scheme 1. Molecular structures of $\mathbf{1}$ and $\mathbf{2}$.

As we shall now demonstrate with $\left[(n-\mathrm{Hex})_{2} \mathrm{~N}\left(1,4-\mathrm{C}_{6} \mathrm{H}_{4}\right)\right] \mathrm{C} \equiv \mathrm{C}\left[\left(1,4-\mathrm{C}_{6} \mathrm{H}_{4}\right) \mathrm{NO}_{2}\right](\mathbf{1})$ and $[(n$ Hex $\left.)_{2} \mathrm{~N}\left(1,4-\mathrm{C}_{6} \mathrm{H}_{4}\right)\right] \mathrm{C} \equiv \mathrm{C}\left(1,4-\mathrm{C}_{6} \mathrm{H}_{4}\right) \mathrm{C} \equiv \mathrm{C}\left[\left(1,4-\mathrm{C}_{6} \mathrm{H}_{4}\right) \mathrm{NO}_{2}\right] \quad$ (2) (Scheme 1), two examples of organic oligo(1,4-phenyleneethynylene)-bridged D-A dyads featuring a terminal nitro group, time-resolved infrared spectroscopy (TRIR) studies of the specific infrared signatures of the alkyne and nitro groups afford a comprehensive picture of the electronic changes taking place subsequent to excitation into the CT band. These dyads were chosen for this study because the dialkylamino moiety is a commonly encountered donor group, the hexyl chains being employed here to ensure sufficient solubility in the (organic) solvent in which the studies were undertaken. 
Furthermore, comparison between $\mathbf{1}$ and $\mathbf{2}$ might facilitate a quantitative measure of the impact of bridge extension upon charge separation in the CT state.

\section{Methods.}

2.1. Ultrafast mid-IR spectrometer. The ultrafast laser system consists of a femtosecond titanium sapphire oscillator (Mai Tai, Spectra Physics) and a high energy titanium sapphire regenerative amplifier (Spitfire Ace, Spectra Physics, 100 fs, 1 kHz, 5 mJ) pumped by Empower $(1 \mathrm{kHz}, 20 \mathrm{~W})$. The $800 \mathrm{~nm}$ beam coming out of Spitfire Ace was divided by beam splitters in order to simultaneously pump Topas Prime with a NirUVis frequency mixer (420 nm excitation wavelength was chosen to selectively excite the CT state in both compounds) and Topas Prime with a DFG mixer (mid-IR probe wavelength with the central wavelength tuned from about 1000 $\mathrm{cm}^{-1}$ until about $3300 \mathrm{~cm}^{-1}$ ). 2DQuick Transient spectrometer (PhaseTech Spectroscopy) was used to record transient spectra. As mid-IR detector MCT array was applied (FPAS-01444, 2 x 64 pixels, Infrared System Development). The dispersion of the spectra were obtained by iHR320 (Horiba) monochromator equipped with set of three grating with different blaze angles and different number of groves per mm ( $8 \mu \mathrm{m}, 75$ grooves $/ \mathrm{mm} ; 6 \mu \mathrm{m}, 100$ grooves $/ \mathrm{mm} ; 4 \mu \mathrm{m}$, 75 grooves $/ \mathrm{mm})$ in order to cover the whole spectral range of interest $\left(1000-3300 \mathrm{~cm}^{-1}\right)$ and to achieve the proper spatial width of the spectrum illuminating MCT array. The angle between polarizations of the pump beam and the probe beam was set at the magic angle $\left(54.7^{\circ}\right)$ in order to avoid rotational effects on measured kinetics. The transient mid-IR experiments were performed with a flow cell (Harrick Scientific) with $0.5 \mathrm{~mm}$ optical path equipped by $2 \mathrm{~mm}$ thick $\mathrm{BaF}_{2}$ front window and the $\mathrm{CaF}_{2} 2 \mathrm{~mm}$ thick back window and the sample volume was about $20 \mathrm{~mL}$. Absorbance of the solution ( $0.5 \mathrm{~mm}$ solution layer) was around 0.3 at the pump wavelength. The instrument response function (IRF) was about $200 \mathrm{fs}$ (measured as the FWHM). The solution 
was purged by dry nitrogen to avoid presence of the oxygen in the solution. Typical pump energy was about $1.5 \mu \mathrm{J}$. The entire set of pump probe delay positions was repeated at least four times in order to improve signal-to-noise ratio and also to check data reproducibility. Ultrafast experiments were repeated on other day to additionally check data reproducibility.

2.2. Synthesis and solvents. Unless otherwise noted in SI, the following conditions apply. All syntheses were carried out using standard Schlenk and glovebox techniques under an argon atmosphere. The solvents used were dried using a solvent purification system (SPS) from Innovative Technology and were degassed and stored over molecular sieves under argon. Deuterated solvents $\left(\mathrm{CDCl}_{3}, \mathrm{C}_{6} \mathrm{D}_{6}\right)$ used for NMR spectroscopy were purchased from Cambridge Isotope Laboratories. $\mathrm{C}_{6} \mathrm{D}_{6}$ was dried over molecular sieve and stored under argon atmosphere before use. N,N-Dihexyl-4-iodoaniline ${ }^{30}$ and 1-ethynyl-4-nitrobenzene ${ }^{31}$ were prepared according to the literature. All other starting materials were purchased from commercial sources and were used without further purification. Characterization and photophysical and photochemical studies of $\mathbf{1}$ and $\mathbf{2}$, together with important remarks regarding experiments in $\mathrm{CH}_{2} \mathrm{Cl}_{2}$, are described in the Supporting Information $\left(\mathrm{SI} ;{ }^{1} \mathrm{H}\right.$ and ${ }^{13} \mathrm{C}\left\{{ }^{1} \mathrm{H}\right\}$ NMR: Figure S1-S2; photophysical studies: Table S1, Figure S3-S6). The solvents for ultrafast studies were spectrophotometric grade from Sigma-Aldrich.

2.3. Calculations. All calculations reported in this work have been carried out using the Gaussian09-D01 suite of programs. ${ }^{32}$ In order to simplify calculations the hexyl chains from compound $\mathbf{1}$ and $\mathbf{2}$ were replaced by methyl groups and the compounds were named as $\mathbf{1}^{`}$ and $\mathbf{2}$ ', respectively. Their geometry optimizations have been performed employing the MPW1PW9133 functional in combination with the 6-31G* basis set. Solvent effects, namely $\mathrm{CH}_{2} \mathrm{Cl}_{2}$, have been simulated by means of the polarizable continuum model (PCM). ${ }^{34}$ Next, TD-DFT calculations 
have been carried out not only to compute the electronic spectra. The geometries of the singlet $\mathrm{S}_{1}$ and $\mathrm{S}_{2}$ states of the molecules under consideration were then optimized. The calculations of the normal modes of vibration of the $S_{0}, S_{1}$ and $S_{2}$ states have subsequently been performed. The UV-visible spectra have been simulated not only at the MPW1PW91 level but also with the CAM-B3LYP ${ }^{35}$ hybrid functional, using the previously optimized $\mathrm{S}_{0}$ geometries. Drawings of molecular structures and molecular orbitals were done using GaussView ${ }^{36}$ program.

\section{Results and discussion.}

As confirmed by TD-DFT calculations (see SI) performed on computationally-simpler model compounds (1' and $\mathbf{2}^{\prime}$ ), in which the hexyl chains have been replaced by methyl groups, compounds $\mathbf{1}$ and $\mathbf{2}$ should possess an (easily discernible) low-energy CT band, while the higherenergy absorption bands should correspond to $\pi^{*} \leftarrow \pi$ transitions (Figure 1a and Table S2). These assignments are consistent with literature reports on similar push-pull compounds. ${ }^{37,38}$ Thus, in $\mathrm{CH}_{2} \mathrm{Cl}_{2}$, the $\mathrm{CT}$ bands are experimentally observed at $423 \mathrm{~nm}$ and $395 \mathrm{~nm}$ while the $\pi^{*} \leftarrow \pi$ transitions are located at $295 \mathrm{~nm}$ and $327 \mathrm{~nm}$ for $\mathbf{1}$ and $\mathbf{2}$, respectively (Figure 1a, Table S1). The TD-DFT study is satisfactory for $\mathbf{1}$ but underestimates the energy of the CT state in $\mathbf{2}$ (Table S2); specifically, it fails to reproduce the experimentally-observed overlap of the two transitions seen with 2 (Figure 1a) ${ }^{39}$ In addition, DFT optimizations (PCM formalism) in the ground state (GS) reveal that the most stable conformation of both compounds in $\mathrm{CH}_{2} \mathrm{Cl}_{2}$ is the fully planar one, i.e. the one optimizing interaction of donor and acceptor end-groups through the $\pi$-electron system. However, given the low activation barriers for rotation around the molecular axis defined by the triple bonds, ${ }^{40,41}$ various conformers might nevertheless be present in solution. 

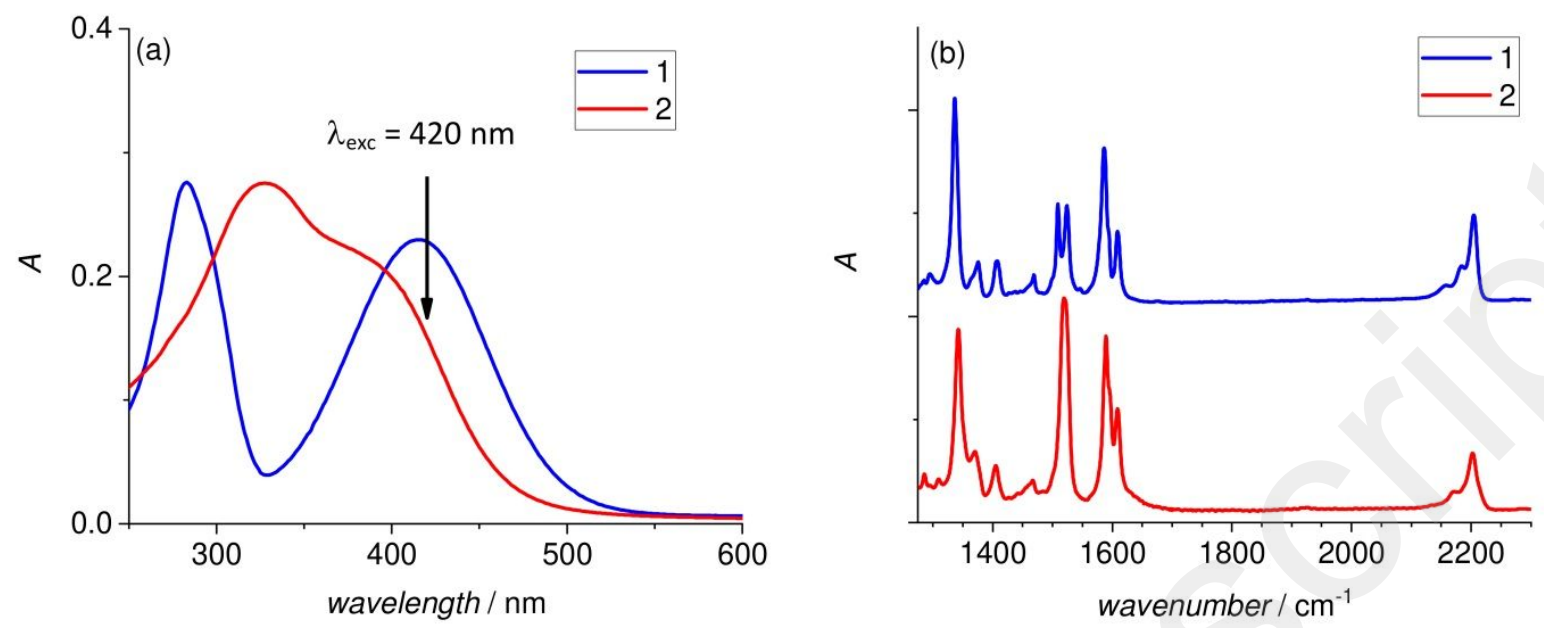

Figure 1. (a) Steady state UV-vis absorption spectra of $\mathbf{1}$ and 2 dissolved in $\mathrm{CH}_{2} \mathrm{Cl}_{2}$. (b) Steady state IR absorption spectra of $\mathbf{1}$ and $\mathbf{2}$ dispersed in a $\mathrm{KBr}$ pellet.

The reporter vibrational modes, the $v(\mathrm{C} \equiv \mathrm{C})$ band and the two $v(\mathrm{~N}=\mathrm{O})$ bands (antisymmetric and symmetric modes) experimentally observed at ca. 2205, 1590 and $1345 \mathrm{~cm}^{-1}$ for $\mathbf{1}$ and $\mathbf{2}$ (Figure 1b and Figure S12e) are fairly accurately modelled in the GS of the DFT studies of $\mathbf{1}^{`}$ and $\mathbf{2}^{`}$ (Table S3). Thus, of the two distinct $\mathrm{v}(\mathrm{C} \equiv \mathrm{C})$ modes calculated for 2 and separated by $20 \mathrm{~cm}^{-1}$ $\left(2187 \mathrm{~cm}^{-1}, 2265 \mathrm{~km} / \mathrm{mol} ; 2207 \mathrm{~cm}^{-1}, 84 \mathrm{~km} / \mathrm{mol}\right)$, only one has a significant intensity, viz. the mode at lowest energy corresponding to the alkyne located closer to the amino group. The second stretching mode expected for 2 might thus correspond to the shoulder on the high energy side of the $v(\mathrm{C} \equiv \mathrm{C})$ band. For both compounds $\mathbf{1}$ and $\mathbf{2}$, additional bands are also present on the low energy side of the main $v(C \equiv C)$ band (Figure $1 \mathrm{~b}$, Figure $\mathrm{S} 12 \mathrm{e}$ ). Due to their significantly weaker intensity, these bands (which are not modelled by DFT) might correspond either to overtones of vibrational modes at lower energy, Fermi resonance bands ${ }^{42}$ or $v(C \equiv C)$ mode(s) of (minor) rotamers of 1 or 2 present in solution at $20{ }^{\circ} \mathrm{C}$. ${ }^{41}$ They were therefore not considered in 
our kinetic modelling. The symmetric and asymmetric $v(\mathrm{~N}=\mathrm{O})$ modes of the nitro group of $\mathbf{1}$ and $\mathbf{2}$ are also fairly well modelled by DFT in the GS using the model compounds $\mathbf{1}$ and $\mathbf{2}$. Based on our calculations for these compounds (Table S3), it appears that the asymmetric $v(\mathrm{~N}=\mathrm{O})$ mode is far less useful than the symmetric mode as an IR-marker. Indeed, besides the fact that it might be experimentally difficult to differentiate the antisymmetric mode from the aromatic $v(C=C)$ modes (Figure S12e), which will also be shifted following photoexcitation into the first excited states, its intensity should be significantly weaker than that of the symmetric stretching mode. ${ }^{43}$ In the following, we have therefore decided to focus our attention on the $v(C \equiv C)$ and symmetric $v(\mathrm{~N}=\mathrm{O})$ modes which should be easier to track than the asymmetric $v(\mathrm{~N}=\mathrm{O})$ mode in TRIR experiments.
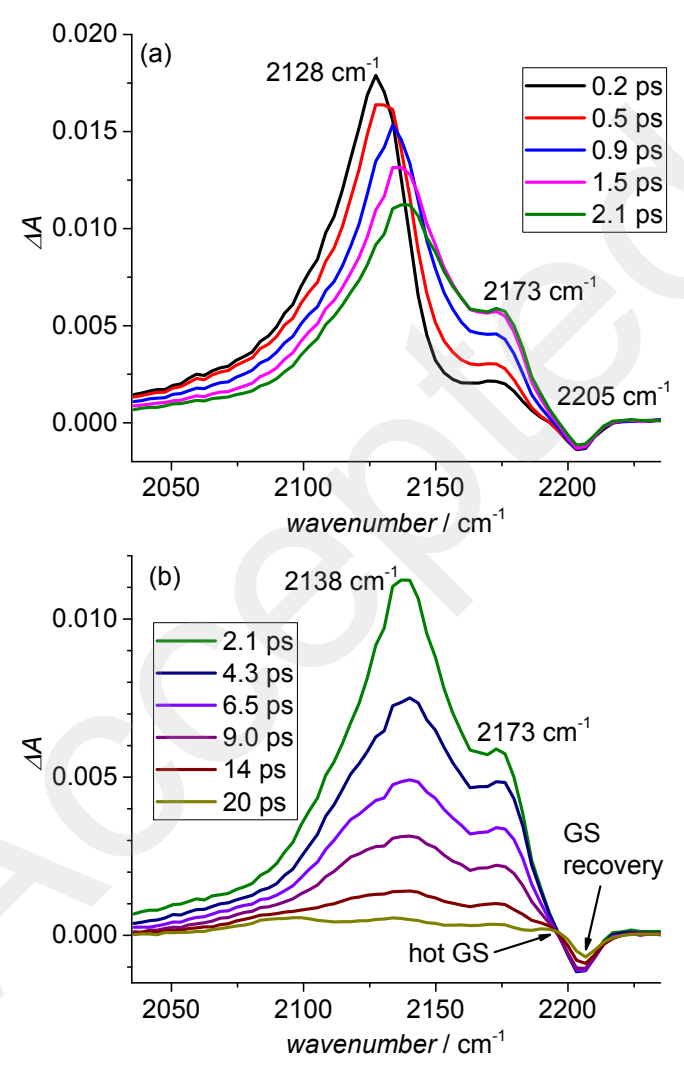


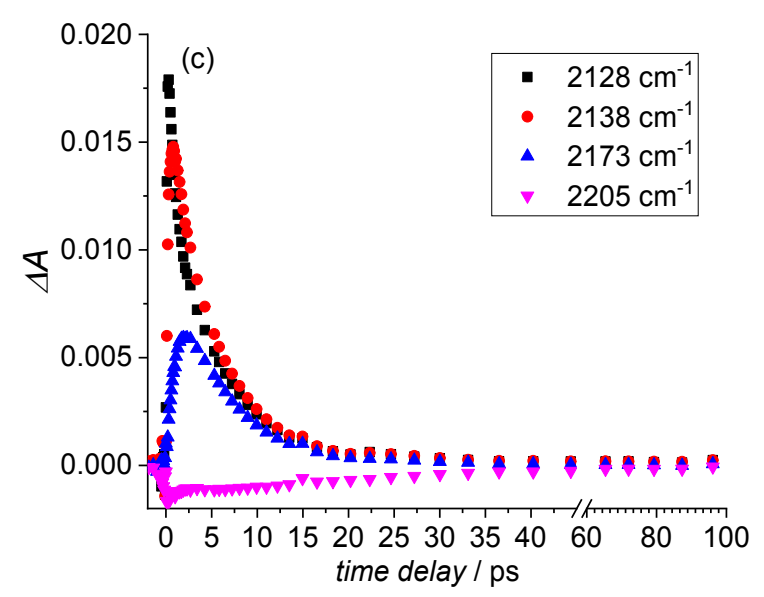

Figure 2. $(\mathrm{a}, \mathrm{b}) \mathrm{TRIR}$ spectra in the spectral range of the $\mathrm{C} \equiv \mathrm{C}$ vibrational marker following electronic excitation into the CT state of 1; time delays specified in the legend. (c) Raw experimental kinetic data recorded for $\mathbf{1}$ at the three selected wavenumbers specified in the legend.

Starting with 1, TRIR absorption spectra were recorded in $\mathrm{CH}_{2} \mathrm{Cl}_{2}$ following electronic excitation at $420 \mathrm{~nm}$, i.e. at a wavelength corresponding to excitation to the CT state of this dyad. The resulting transient spectra recorded in the spectral range of the $\mathrm{C} \equiv \mathrm{C}$ stretching vibrations are presented in Figure 2 and Figure S13. Following excitation, a strong positive band develops at $2128 \mathrm{~cm}^{-1}$ within the duration of the laser pulse, and a relatively weak negative band forms at $2205 \mathrm{~cm}^{-1}$ on a comparable timescale (Figure 2a), the latter corresponding to partial depopulation of the GS caused by the electronic excitation. The $2205 \mathrm{~cm}^{-1}$ band is well-resolved because it does not overlap spectrally with the positive band of much higher intensity. This negative band, formed just after excitation, has a similar amplitude (of the order of $1.3 \times 10^{-3}$ : Figure S14a) to that of many other organic compounds, ${ }^{44}$ including that of a recently investigated triazine-based dyad. ${ }^{10}$ As the intensity of an IR band is correlated with the square of the change 
in the local dipole moment, the much stronger positive band (ca. 14 times more intense than the negative band: Figure S14a) must be related to a stronger local change of the dipole moment for this $\mathrm{C} \equiv \mathrm{C}$ group after electronic excitation. The computational study afforded a similar outcome; the calculated intensity for the $\mathrm{C} \equiv \mathrm{C}$ vibration in the ground state $(1995 \mathrm{~km} / \mathrm{mol}$ : Table S3) being far less intense than that of the first singlet excited state $(11041 \mathrm{~km} / \mathrm{mol}$ : Table S3). Note, though, that the calculated intensity in the singlet excited state is for the relaxed structure, while experimentally the initial positive signal must correspond to the Franck-Condon (FC) state. The $77 \mathrm{~cm}^{-1}$ shift to low-energy of the $2205 \mathrm{~cm}^{-1}$ band to afford the $2128 \mathrm{~cm}^{-1}$ band provides clear evidence of a weakening of this $\mathrm{C} \equiv \mathrm{C}$ bond in the singlet $\mathrm{C}$ T state, suggesting a partial population (depopulation) of the antibonding $\pi^{*}$ (bonding $\pi$ ) alkyne-based molecular orbitals (MOs) in the excited CT state. Subsequent to its rise, the $2128 \mathrm{~cm}^{-1}$ band undergoes a simultaneous partial decay and blue shift to $2138 \mathrm{~cm}^{-1}$ (Figure 2a). Finally, the $2138 \mathrm{~cm}^{-1}$ band decays in an exponential way (Figure 2c, Figure S15, Table S7) with a time constant of about 5.6 ps. The initial spectral shift and narrowing of the nascent $2128 \mathrm{~cm}^{-1}$ band is consistent with vibrational cooling of the newly formed excited state. As the $2128 / 2138 \mathrm{~cm}^{-1}$ band experiences a fast initial decay (time constant of the order of $1 \mathrm{ps),} \mathrm{a} \mathrm{new} \mathrm{(positive)} \mathrm{band} \mathrm{forms} \mathrm{with} \mathrm{a} \mathrm{maximum} \mathrm{at} 2173$ $\mathrm{cm}^{-1}$ (Figure 2a, Figure S15b, Table S7). After a further ca. $1 \mathrm{ps}$, during which the $2173 \mathrm{~cm}^{-1}$ band reaches its maximum, both bands $\left(2138 / 2173 \mathrm{~cm}^{-1}\right)$ decay with similar time constants of ca. 6 ps (Figure 2b,c, Figure S15b,d, Table S7). These observations suggest that the underlying excited species are in rapid equilibrium. Because the second band is at a slightly higher energy, which is consistent with a comparatively greater multiple C-C bond order, we tentatively attribute this second band to the formation of a non-planar rotamer that possibly corresponds to a twisted intramolecular charge-transfer (TICT) state; we note that a TICT state will facilitate 
charge separation in the excited state. ${ }^{45}$ This second band is still significantly more intense than the negative band at $2205 \mathrm{~cm}^{-1}$. According to our calculations (Table S3), the latter corresponds to the $\mathrm{r}(\mathrm{C} \equiv \mathrm{C})$ mode expected for the fully relaxed state of the lowest singlet state (calculated to be at $2106 \mathrm{~cm}^{-1}$ for $\mathbf{1}$ ), derived from population of the singlet state after relaxation. In contrast with this result, a planar conformation was calculated for the first excited state of tolane, ${ }^{46,47}$ but in the present case the twisted conformation adopted for the $S_{1}$ state following relaxation may result from the presence of the push-pull substituents at the para-positions of the terminal phenyl rings. While exact correspondence of computational and experimental data cannot be expected given the use of a slightly different model compound (1), both the increase in intensity of the $v(\mathrm{C} \equiv \mathrm{C})$ mode in the relaxed singlet state and its shift to lower energy are qualitatively supported by the DFT calculations.

After about 18 ps, when both of these positive bands have almost decayed (Figure S13c), the spectral features of the remaining transients are consistent with (i) the formation of a vibrationally-excited (hot) GS (band at ca. $2190 \mathrm{~cm}^{-1}$ ) and with (ii) the formation of a longerlived excited state exhibiting a $\mathrm{C} \equiv \mathrm{C}$ stretching mode at even lower energy that that corresponding to its initially populated CT $\left(\mathrm{S}_{1}\right)$ state $\left(\mathrm{ca} .2100 \mathrm{~cm}^{-1}\right.$ : Figure $\left.\mathrm{S} 13 \mathrm{c}\right)$. The negative signal at ca. $2205 \mathrm{~cm}^{-1}$ corresponds to depopulation of the GS, while the positive signal (ca. $2190 \mathrm{~cm}^{-1}$ ) is related to the formation of the aforementioned hot ground state as the recovery of the ground state takes place. ${ }^{48,49}$ These spectral changes are direct evidence of the presence of a fast and efficient internal conversion (IC) following electronic excitation. All spectral changes resulting from recovery of the GS are completed after ca. $50 \mathrm{ps,} \mathrm{a} \mathrm{period} \mathrm{typical} \mathrm{for} \mathrm{vibrational}$ cooling (VC) of organic compounds in solution, ${ }^{48,49}$ although some depopulation of the ground state is still visible (Figure S13c, Figure S14b), indicating that not all excited molecules have 
relaxed to the GS. The negative band (amplitude ca. $1.5 \times 10^{-4}$ : Figure S14b) persists beyond 106 ps, suggesting partial decay of the initially populated singlet states into longer-lived transients which probably correspond to triplet states. ${ }^{10}$ The ratio of the final amplitude of the negative band at $2205 \mathrm{~cm}^{-1}\left(1.5 \times 10^{-4}\right.$ : Figure S14b) to the initial amplitude of this band $\left(1.3 \times 10^{-3}\right.$ : Figure S14a) is 0.12 , so the estimated quantum yield of the IC is 0.88 .

Apart from these spectral changes corresponding to IC and to VC to the GS, the relatively weak positive band which develops at ca. $2100 \mathrm{~cm}^{-1}$ (Figure S13c, Figure S14b) can be assigned to a longer-lived state. This relatively weak, positive band, initially masked by the strong band formed by the singlet excited state, becomes apparent after $18 \mathrm{ps,} \mathrm{by} \mathrm{which} \mathrm{time} \mathrm{the} \mathrm{singlet}$ excited state has largely decayed. This new band persists up to 100 ps and longer (Figure S13c, Figure S14b). Based on the extended lifetime of the excited state giving rise to this new $C \equiv C$ stretching mode and on our calculations, this signal may correspond to the formation of the first triplet state(s) of $1 .{ }^{10}$ The $\mathrm{C} \equiv \mathrm{C}$ stretch of the first triplet state is calculated to be at $2048 \mathrm{~cm}^{-1}$ by DFT i.e. at a lower energy than the $\mathrm{C} \equiv \mathrm{C}$ stretch of the relaxed singlet state $\left(2106 \mathrm{~cm}^{-1}\right.$ : see Table S3).

Our next goal was to detect the fate of the $\mathrm{NO}_{2}$ symmetric vibration following the electronic excitation of $\mathbf{1}$. After the photoinduced charge transfer to the nitro group, this vibration should be shifted to lower energy. The strong $\mathrm{NO}_{2}$ symmetric vibration is observed at $1342 \mathrm{~cm}^{-1}$ in the GS, a spectroscopic region devoid of other intense vibrations (Figure S12e). Calculations for 1 predict that this IR marker is located at $1042 \mathrm{~cm}^{-1}$ in the first singlet excited state after vibrational relaxation (Table S3). The corresponding experimental signal was eventually detected at $1048 \mathrm{~cm}^{-1}$ (Figure 3a), following a kinetic evolution (increase and decrease) with 
similar time constants to those of the $v(\mathrm{C} \equiv \mathrm{C})$ mode attributed to the singlet excited state (Figure $3 b$, Figure S16 and Table S8). The shorter time constant corresponding to its fast decay $(\sim 0.85$ ps) is attributed to relaxation of the Franck-Condon state, and the longer time constant ( $\sim 5.9 \mathrm{ps})$ is suggested to correspond to the lifetime of this excited singlet state, once relaxed. Thus, we can assign the $1048 \mathrm{~cm}^{-1}$ band as the $\mathrm{NO}_{2}$ symmetric vibration of the vertical singlet state. The increase in intensity of this signal appears to be delayed relative to the corresponding increase in the signal of the singlet state $v(\mathrm{C} \equiv \mathrm{C})$ vibration (Figure $\mathrm{S} 17$ ). We will return to this particular observation later. Similar to the $v(\mathrm{C} \equiv \mathrm{C})$ vibration, a new band assignable to the longer-lived transients was also detected in the spectral range of the $\mathrm{NO}_{2}$ symmetric vibration (Figure S18) after all spectral changes related to the decay of the excited singlet state and VC were complete. Based on its persistence, this very weak band is suggested to correspond to the triplet state, for which the symmetric $\mathrm{N}-\mathrm{O}$ mode is expected in this spectral range based on our computations (1049 $\mathrm{cm}^{-1}$, Table S3).

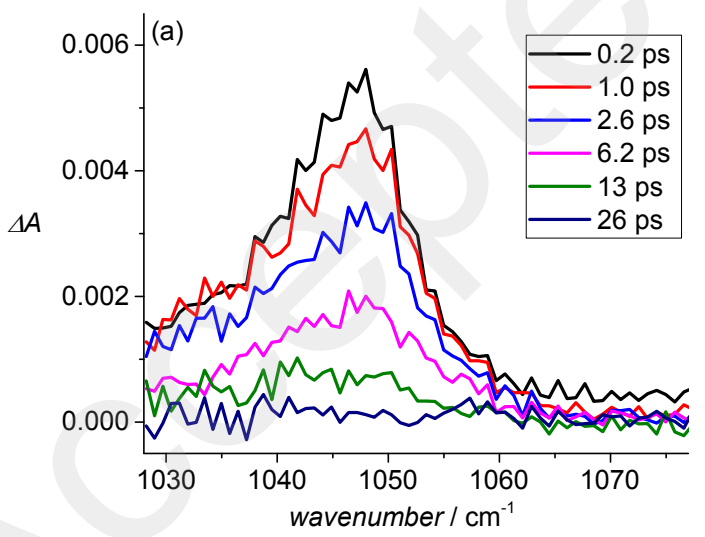




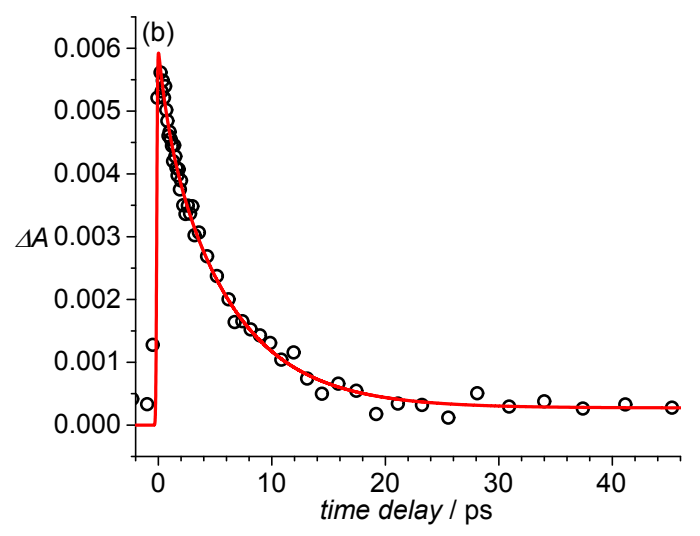

Figure 3. (a) TRIR spectra in the spectral range of the symmetrical $\mathrm{NO}_{2}$ vibrational marker, following electronic excitation into the CT state of 1; time delays specified in the legend. The sharp features on the time-resolved spectra are due to an experimental artefact caused by the detection system employed. (b) Kinetic data recorded at $1048 \mathrm{~cm}^{-1}$.

The presence of an efficient IC process, depopulating the excited singlet state(s) for $\mathbf{1}$, is also suggested by the spectroscopic data gathered in the spectral range of the $\mathrm{NO}_{2}$ symmetric vibration in the GS (Figure S19). A negative band at $1342 \mathrm{~cm}^{-1}$, formed within the duration of the laser pulse, is related to the depopulation of the GS of $\mathbf{1}$ due to the electronic excitation. The temporal spectral evolution recorded in this spectral range supports the presence of an efficient IC process, which first forms the hot ground state, and which subsequently, via VC, recovers the population of the GS. The time constants of these spectral changes are consistent with those reported for other organic compounds (Figure S19c,d). ${ }^{48,49}$ After ca. 80 ps, when all processes related to $\mathrm{VC}$ are over, there still exists a weak and negative signal (that persists beyond $3 \mathrm{~ns}$ ) at $1342 \mathrm{~cm}^{-1}$ evincing some GS depopulation (Figure S19b). A weak positive band with a maximum at $1347 \mathrm{~cm}^{-1}$ (overlapping partially with the negative band) is also detected, but its origin has not yet been clearly established. 

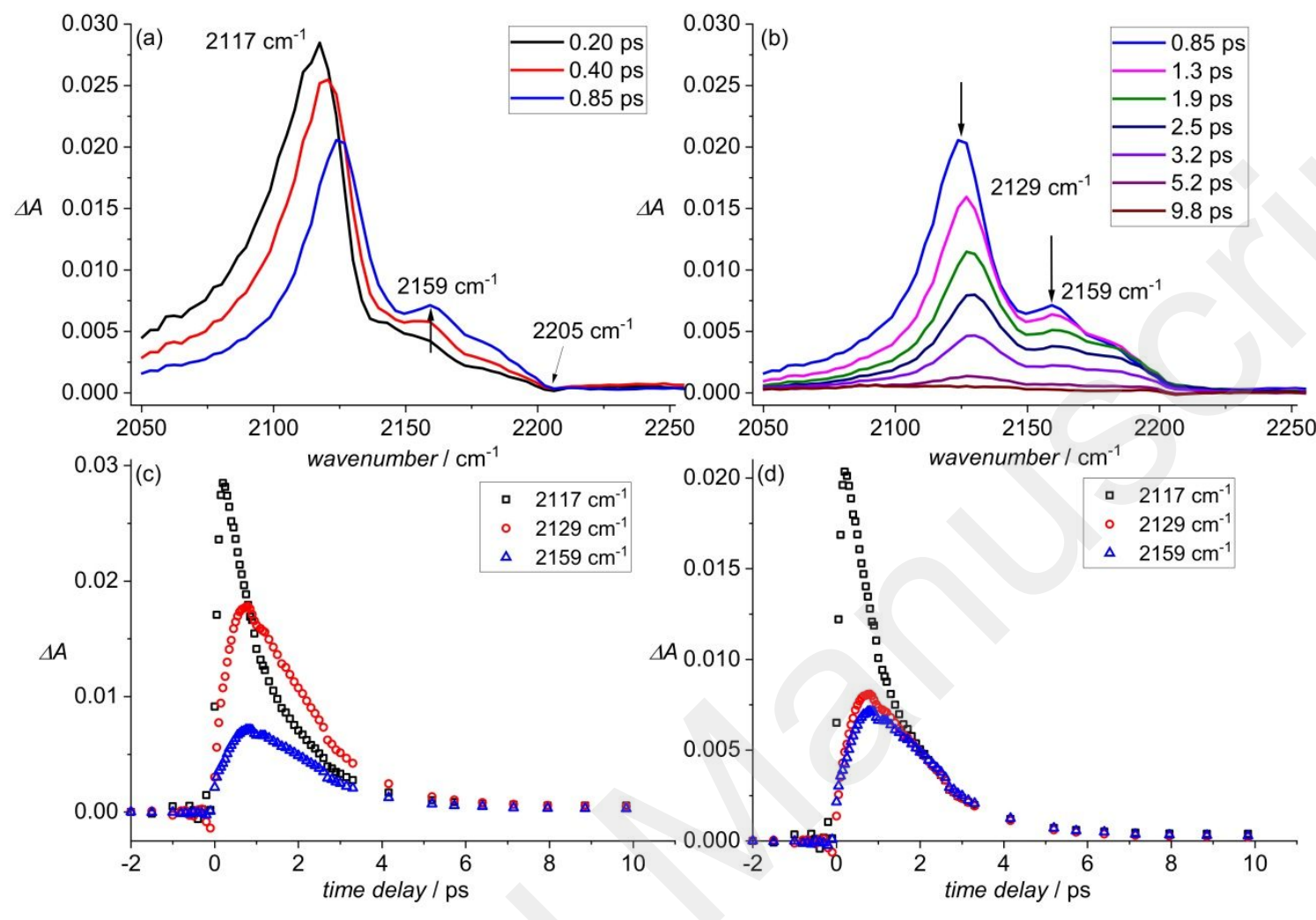

Figure 4. (a-b) TRIR spectra in the spectral range of the $\mathrm{C} \equiv \mathrm{C}$ vibrational marker following electronic excitation into the CT state of 2; time delays specified in the legend. (c) Raw experimental kinetic data recorded for $\mathbf{2}$ at the three selected wavenumbers specified in the legend. (d) Normalized experimental kinetic data recorded for $\mathbf{2}$ at the three selected wavenumbers specified in the legend

The longer homologue 2 was then investigated by TRIR spectroscopy. In the $v(C \equiv C)$ spectral range, the situation with this compound was expected to be slightly more complex, because two stretching modes instead of one were expected to be infrared-active in the excited states. Indeed, 
DFT calculations predict two distinct $v(\mathrm{C} \equiv \mathrm{C})$ modes separated by ca. $10 \mathrm{~cm}^{-1}$ for 2 in the first singlet state (following relaxation) (Table S3: $2134 \mathrm{~cm}^{-1}, 13006 \mathrm{~km} / \mathrm{mol} ; 2145 \mathrm{~cm}^{-1}, 62780$ $\mathrm{km} / \mathrm{mol}$ ). These modes are calculated to be at slightly lower energy than the corresponding modes for the GS (Table S3, $2187 \mathrm{~cm}^{-1}$ and $2207 \mathrm{~cm}^{-1}$ ). There is a significant increase in intensity for each $v(\mathrm{C} \equiv \mathrm{C})$ mode in the first singlet state of $\mathbf{2}$ (following relaxation). In contrast to the ground state, the most intense of these two modes in the singlet excited state is that at lowest energy, a mode which is dominated by the stretching motion of the triple bond closer to the nitro group. This observation is consistent with this triple bond being the more polarized when the charge-transfer state is populated. The first singlet state of $2^{\prime}$ is computed to adopt a fully planar conformation after vibrational relaxation, in contrast to the $S_{1}$ state of $\mathbf{1}$ ' which was shown to adopt a twisted (perpendicular) conformation around the central $\mathrm{C} \equiv \mathrm{C}$ bond. This computational result for $\mathbf{2}^{\mathbf{2}}$ resembles that reported for the "parent" 1,4bis(phenylethynyl)benzene..$^{21}$

Close inspection of the spectral changes in the $v(C \equiv C)$ region reveals the growth of one rather than two $v(\mathrm{C} \equiv \mathrm{C})$ bands (maximum at $2117 \mathrm{~cm}^{-1}$ : Figure 4a). Note, though, that two modes separated by $10 \mathrm{~cm}^{-1}$ are predicted by the calculations, and these might not have been resolved under our experimental conditions, especially if one of them is far less intense than the other. As observed for $\mathbf{1}$, this new positive band at $2117 \mathrm{~cm}^{-1}$ shifts to $2129 \mathrm{~cm}^{-1}$ and then decays, giving rise to another band at ca. $2159 \mathrm{~cm}^{-1}$ (Figure 4a) which increases in intensity and then decays at a similar rate to the band at $2129 \mathrm{~cm}^{-1}$ (Figure $4 \mathrm{~b}$, Figure S21, Table S9). Analogous to $\mathbf{1}$, the second band at slightly higher energy $\left(2159 \mathrm{~cm}^{-1}\right)$ can be attributed to the formation of the TICT state. The observed spectral changes suggest that this transient species also coexists in rapid equilibrium with the planar CT state (which in this case is the relaxed $\mathrm{S}_{1}$ state, as indicated by 
DFT calculations). The decay of these initially-populated singlet states is significantly faster for 2 than for 1 (ca. 1 ps: Figure 4c-d, Figure S21, Table S9).

A larger spectral shift of the (positive) band in the $S_{1}$ state from the position of this vibration in the GS is observed for the $v(C \equiv C)$ mode $(\mathrm{s})$ of $\mathbf{2}\left(88 \mathrm{~cm}^{-1}\right)$ compared to that of $\mathbf{1}\left(77 \mathrm{~cm}^{-1}\right)$. Similar to observations with $\mathbf{1}$, a transient at ca. $1049 \mathrm{~cm}^{-1}$ is observed for 2 which exhibits kinetic behavior closely related to that of the $v(C \equiv C)$ band attributed to the $\mathrm{S}_{1}$ state (Figure S22S23b). Although somewhat wider than the band previously observed for $\mathbf{1}$ in the same spectral range (Figure S25), this signal can be similarly assigned to the symmetric stretching mode of the nitro group in the $S_{1}$ state of $\mathbf{2}$. Analogous to $\mathbf{1}$, its growth occurs slightly later than that of the signals corresponding to the $v(\mathrm{C} \equiv \mathrm{C})$ stretching mode (Figure $\mathrm{S} 23 \mathrm{~b}$ ). In qualitative agreement with these experimental observations, DFT calculations on the relaxed $S_{1}$ state of 2 indicate that the $v(C \equiv C)$ mode $(s)$ should be more intense and should occur at lower energy than in the GS. Calculations of the $v(\mathrm{~N}=\mathrm{O})$ symmetric mode $\left(1040 \mathrm{~cm}^{-1}\right.$ : Table S3) correspond closely with the energy observed for this transient of $2\left(1049 \mathrm{~cm}^{-1}\right.$, Figure S22a).

Finally, and also reminiscent of observations with $\mathbf{1}$, the overall decay process of the CT state of 2 affords strong evidence for a very efficient IC process followed by hot GS formation and then recovery of the GS (Figure S20d). As with 1, some depopulation of the GS persists (Figure S20f) beyond $3 \mathrm{~ns}$ (the time range of our spectrometer); the ratio of the final amplitude of the negative band at $2205 \mathrm{~cm}^{-1}\left(6 \times 10^{-5}\right.$ : Figure S20f $)$ to the initial amplitude of this band $\left(5 \times 10^{-4}\right.$ : Figure S20e) is also ca. 0.12, so the estimated quantum yield of the IC is 0.88 . As previously observed with $\mathbf{1}$, transient spectra recorded in the spectral range of the $v(C \equiv C)$ vibrations do not completely decay (at least within the 3 ns available in our spectrometer), but instead give rise to 
another and longer-lived excited state, evidenced by the appearance of a new $\mathrm{C} \equiv \mathrm{C}$ absorption at $2109 \mathrm{~cm}^{-1}$ (Figure S20d). This weak positive band, already visible after $5 \mathrm{ps,} \mathrm{is} \mathrm{even} \mathrm{more}$ apparent after 9 ps (by which time the singlet excited state has completely decayed), and it persists for more than 50 ps, suggesting a partial decay of the initially populated singlet states into this longer-lived transient. This persistent signal also exhibits a spectral evolution typical of the $\mathrm{VC}$ of a nascent state (Figure $\mathrm{S} 20 \mathrm{~d}$ ). By analogy with $\mathbf{1}$, this new $\mathrm{C} \equiv \mathrm{C}$ stretching mode might therefore be related to the formation of a triplet state(s). ${ }^{10}$ Similar to observations with $\mathbf{1}$, a very weak and persistent band in the $\mathrm{N}-\mathrm{O}$ symmetric vibration region was observed over longer time delays (Figure S24) which, based on our DFT calculations (Table S3), might be attributed to the $\mathrm{N}-\mathrm{O}$ symmetric mode of the triplet state. Once again, and similar to observations with $\mathbf{1}$, the presence of an IC process and depopulation of the excited singlet state(s) of 2 is well evidenced in the spectral range corresponding to the symmetric vibration of the nitro group in the GS (Figure S26).

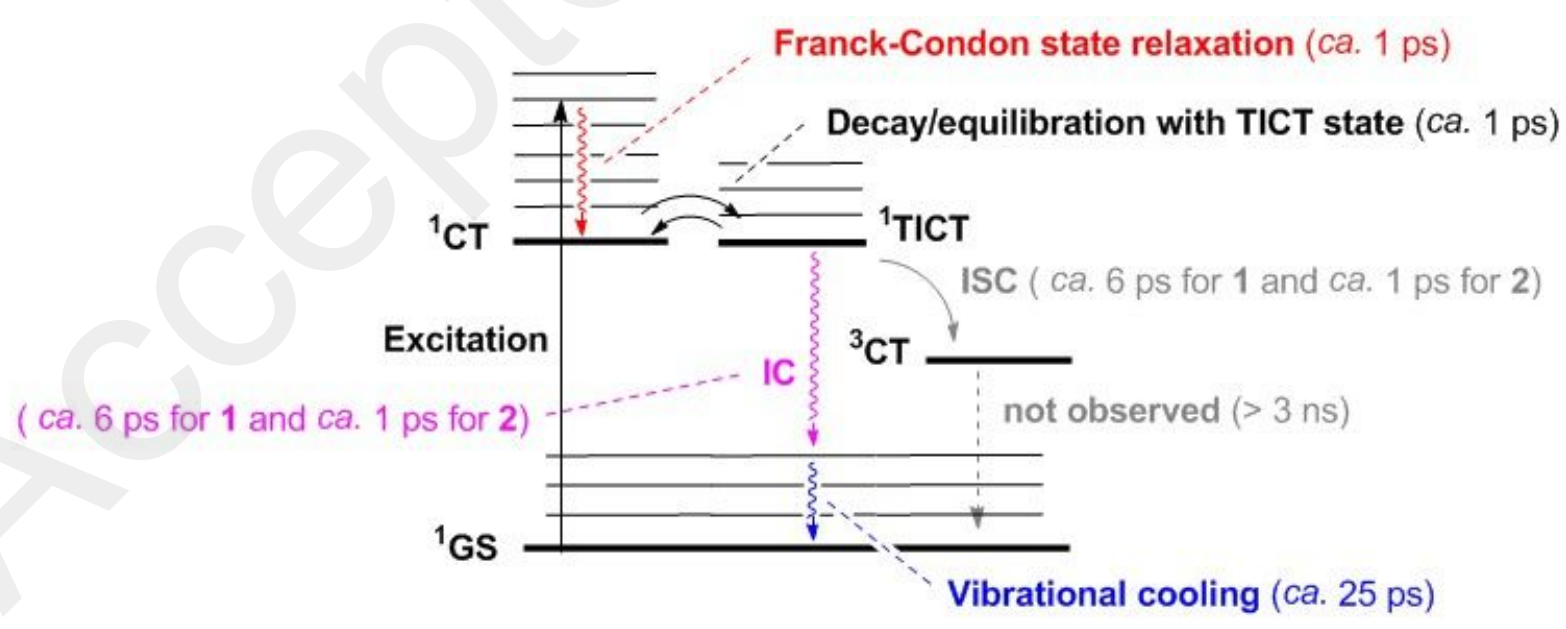


Scheme 2. Proposed processes underlying the spectroscopic IR changes observed for $\mathbf{1}$ and $\mathbf{2}$ subsequent to excitation into the singlet CT manifold.

From the above observations, we propose Scheme 2 to rationalize the spectroscopic behavior of 1 and 2 subsequent to excitation at $420 \mathrm{~nm}$. Some of the structural changes undergone in the first excited states of $\mathbf{1}$ and $\mathbf{2}$ can now be addressed based on the available IR data.

The position of the $\mathrm{C} \equiv \mathrm{C}$ vibrational mode is the same for $\mathbf{1}$ and $\mathbf{2}$ in the GS $\left(2205 \mathrm{~cm}^{-1}\right)$. In contrast, the relaxed singlet excited-state bands are located at $2138 \mathrm{~cm}^{-1}$ and $2129 \mathrm{~cm}^{-1}$ while the second positive bands are located at $2173 \mathrm{~cm}^{-1}$ and $2159 \mathrm{~cm}^{-1}$ for $\mathbf{1}$ and $\mathbf{2}$, respectively (Figure S27-S28). ${ }^{50}$ Overall, despite small differences, these shifts reflect a fairly comparable decrease in the triple bond order of the alkyne bridge, suggesting that some of the electron density delocalized from the amino donor group during the CT process remains localized in the $\pi^{*}$ molecular orbitals (MO) of the $\mathrm{C} \equiv \mathrm{C}$ bonds, while some of the electronic density in the $\pi$ MO of the $\mathrm{C} \equiv \mathrm{C}$ bond is delocalized toward the nitro acceptor group. These data are consistent with the valence-bond (VB) representation of the CT state usually proposed for these dyads (Scheme 3), ${ }^{1,51}$ although the decrease in the C-C bond order is less pronounced than the simplistic VB representation would suggest. This phenomenon is more qualitatively illustrated by the differential density plots between $S_{1}$ and $S_{0}$ for $\mathbf{1}^{\prime}$ and 2' (Figure S7), although these plots correspond to the Franck-Condon state, not the relaxed CT state.

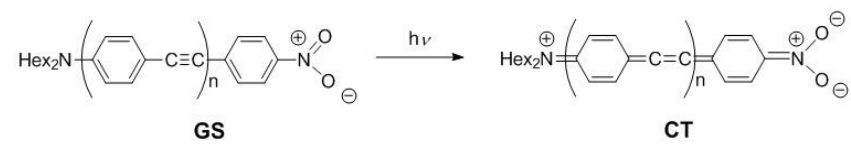

Scheme 3. Valence-bond representation of the CT state for $\mathbf{1}(n=1)$ and $\mathbf{2}(\mathrm{n}=2)$. 
In contrast to observations made with the $v(\mathrm{C} \equiv \mathrm{C})$ modes, a much larger decrease in energy is observed for the symmetric $v(\mathrm{~N}=\mathrm{O})$ mode of the nitro group for both compounds (ca. $295 \mathrm{~cm}^{-1}$ ) upon proceeding to the excited state, reflecting a more significant decrease in the $\mathrm{N}=\mathrm{O}$ bond order than the $\mathrm{C} \equiv \mathrm{C}$ bond order (Table $\mathrm{S} 4-\mathrm{S} 5$, Figure $\mathrm{S} 9-\mathrm{S} 10$ ). This experimental shift is supported by DFT calculations on $\mathbf{1}^{`}$ and $\mathbf{2}^{`}$ (Table S3). The electron density changes suggested by the VB representation of the CT state are also reflected in the differential density plots between the $S_{1}$ and $S_{0}$ states that were obtained for 1' and 2' (Figure S7). Both plots clearly reveal that most of the charge is transferred from the nitrogen lone pair of the amino group and the $\pi$ system of the adjacent aryl group toward the (most) remote aryl ring and the oxygen atoms of the nitro group. The similar shifts of the symmetric $v(\mathrm{~N}=\mathrm{O})$ modes found for $\mathbf{1}$ and $\mathbf{2}$ following excitation to the CT state suggest that similar electron density resides on the acceptor group after Franck-Condon relaxation, in spite of the fact that the electronic coupling between the donor and acceptor groups in these dyads should significantly decrease upon progressing from 1 to $2 .{ }^{52}$ This conclusion is also consistent with the close similarity between these shifts (ca. $\left.295 \mathrm{~cm}^{-1}\right)$ and that found for the symmetric $v(\mathrm{~N}=\mathrm{O})$ mode of the reduced nitro group following one-electron reduction of closely-related nitroaromatics. ${ }^{27,28}$ The latter observation confirms that the $\mathrm{N}-\mathrm{O}$ stretching modes are perturbed in a very similar way in the CT state (after vibrational cooling) to that when one additional electron is transferred to the nitroaryl unit, although less than one electron is actually localized on the "reduced" nitro group in all of these cases. ${ }^{51}$ The electronic couplings between donor and acceptor will determine the amount of charge instantly transferred between the two sides of the molecule in the Franck-Condon state, whereas it is the change in local charge (Tables S4-S5, Figure S9) residing on the nitrogen and oxygen atoms of the nitro group after vibrational relaxation that determines the shift of the $v(\mathrm{~N}=\mathrm{O})$ modes (i.e. the 
change in bond order between the nitrogen and oxygen atoms). Consistent with this interpretation, the density differential plots between $S_{0}$ and $S_{1}$ for 1' and 2' (Figure $S 7$ ) reveal that the amount of charge transferred during the vertical $\mathrm{CT}$ process depends on the bridge length. This amount decreases upon bridge extension (0.826 e for 1' vs. 0.661 e for 2'). In contrast, the N-O computed bond-order changes between the GS and the vibrationally relaxed CT state remain fairly constant for 1' and 2' (Figure S10), in line with the constancy of the IR shifts observed for the $\mathrm{N}-\mathrm{O}$ stretching modes of $\mathbf{1}$ and $\mathbf{2}$. These findings confirm that the symmetric $v(\mathrm{~N}=\mathrm{O})$ mode of the nitro group, likewise to the $v(\mathrm{C} \equiv \mathrm{C})$ mode, constitutes a reliable IR marker for monitoring the bonding changes between specific atoms of the nitro group induced by the CT process in these dyads.

Compared to the initial transients detected for $\mathbf{1}$ and $\mathbf{2}$ (believed to correspond to the lowest singlet states), much less spectroscopic data is available on the longer-lived transients (believed to correspond to the triplet states). The slower decay and lower concentration of the species at the origin of these signals make them more difficult to detect by TRIR spectroscopy. The weak red-shifted $v(\mathrm{C} \equiv \mathrm{C})$ mode indicates a further weakening of the bond order within their alkyne linkers, in qualitative agreement with calculations made for the lower triplet states of model complexes 1' and 2'. The latter are consistent with diradical states featuring unpaired spins partly delocalized on the bridge. ${ }^{53}$ Our calculations predict a weak signal located at ca. $1049 \mathrm{~cm}^{-1}$ for $\mathbf{1}$, and ca. $1079 \mathrm{~cm}^{-1}$ for $\mathbf{2}^{\prime}$ corresponding to the symmetric $\mathrm{v}(\mathrm{N}=\mathrm{O})$ mode of these triplet states. In accordance with these theoretical predictions, weak signals were experimentally detected in this spectral range for both 1 and 2. 
The difference in the relaxation rates for the $S_{1}$ states of $\mathbf{1}$ and $\mathbf{2}$ is still unclear, as is the origin of the slight delay observed between the increase in the intensity of the $v(C \equiv C)$ modes and the $v(\mathrm{~N}=\mathrm{O})$ modes in the singlet states. The discrepancy in relaxation rates may stem from the different conformations adopted by these dyads in their respective $S_{1}$ states after vibrational relaxation. Both adopt a fully planar conformation in their ground and $\mathrm{T}_{1}$ states, and the slower kinetic behavior for $\mathbf{1}$ may result from the need for rotation from the TICT state to the required planar geometry for internal conversion and intersystem crossing, a motion not needed with $\mathbf{2}$ for which the relaxed CT state is also planar. The delay observed in the singlet states between the increase in intensity of the $v(\mathrm{C} \equiv \mathrm{C})$ and $v(\mathrm{~N}-\mathrm{O})$ modes (Figure S23) could manifest vibrational energy transfer. This could occur via vibrational cascade (percolation down the energy levels) or "through-bond" transfer (anharmonic coupling with solvent), but in either case the peak population of the $v(\mathrm{~N}=\mathrm{O})$ mode would be delayed with respect to that of the $v(\mathrm{C} \equiv \mathrm{C})$ mode. The observed delay of $0.5 \mathrm{ps}$ is in fact surprisingly close to the value reported in the literature for modes separated by a few hundred wavenumbers. ${ }^{54}$ These important observations will be the subject of future investigations.

\section{Conclusions}

In summary, two nitro-substituted donor-acceptor oligo(phenyleneethynylene)-bridged dyads 1 and 2 were studied by time-resolved infrared (TRIR) spectroscopy. The nitro and alkyne functional groups were used as vibrational reporters to study the photo-induced charge-transfer process in these archetypal push-pull dyads. Overall, very similar spectral changes were experimentally found for these two compounds. Following excitation into their charge-transfer (CT) states, a fast decay ( $\sim 6 \mathrm{ps}$ for $\mathbf{1}$ and $\sim 1 \mathrm{ps}$ for 2$)$ due to the presence of the very efficient 
and fast IC process (major pathway) is observed, while simultaneously the formation of longerlived transient species (minor pathway) is observed, probably corresponding to triplet states. Although the nitro group is often avoided in model compounds for ultrafast transient studies because it quenches luminescence in polar solvents, we have shown here that, from the viewpoint of transient vibrational investigations based on absorption, the nitro group constitutes an outstanding reporter for studying photo-induced charge-transfer processes. From a structural perspective, the shifts to lower wavenumbers observed for both the $v(C \equiv C)$ and $v(N-O)_{\text {sym }}$ modes in the present study reveal a weakening of these modes in the singlet excited states, in line with expectations based on classic VB representations traditionally advanced for CT states. Consistent with the computed bond orders in the singlet excited states (Figure S9), the observed shifts of the symmetric N-O stretching mode suggest that a similar degree of charge transfer to the nitro group in the CT state for both dyads, despite the different length bridges connecting the donor to the acceptor groups. The spectroscopic changes of the nitro group during this process resemble those observed upon one-electron reduction, consistent with the changes having resulted from the addition of (nearly) one electron to the acceptor, and despite the decrease in charge transferred from donor to acceptor group across a lengthened molecular bridge. We conclude that the nitro group is a reliable local marker of charge, and anticipate that this underutilized resource will be more commonly used in TRIR investigations aimed at modeling dyads featuring strong acceptor groups in the future. The study of further derivatives is currently underway in our group to define the scope of the utility of the nitro reporter and to further rationalize the various experimental decay rates for the CT states of $\mathbf{1}$ and $\mathbf{2}$.

\section{ASSOCIATED CONTENT}

\section{Supporting Information.}


The Supporting Information is available free of charge on the ACS Publications website. Femtosecond transient absorption mid-IR spectrometer used, synthesis of compounds and characterization, NMR spectra of the compounds, TD-DFT calculations (PDF), transient absorption spectra and kinetic studies.

\section{AUTHOR INFORMATION}

\section{Notes}

The authors declare no competing financial interests.

Jacek Kubicki, ORCID: 0000-0003-0790-5876

Frédéric Paul: ORCID: 0000-0002-8256-0129

\section{ACKNOWLEDGMENT}

J.K. acknowledges financial support from the Ministry of Science and Higher Education. The CNRS (LIA Redochrom - $\mathrm{N}^{\circ}$ 1194) is acknowledged for financial support. M.G.H. thanks the Australian Research Council for financial support (grant no. DP170100408). T.B.M. thanks the Julius-Maximilians-Universität Würzburg for support. A.G. thanks the University of the Philippines for financial support.

\section{REFERENCES}

(1) Bures, F. Fundamental Aspects of Property Tuning in Push-Pull molecules. RSC Adv. 2014, 4, 58826-58851. 
(2) Lyu, S.; Farré, Y.; Ducasse, L.; Pellegrin, Y.; Toupance, T.; Olivier, C.; Odobel, F. PushPull Ruthenium Diacetylide Complexes: New Dyes for p-Type Dye-Sensitized Solar Cells. RSC Adv. 2016, 6, 19928-19936.

(3) Massin, J.; Lyu, S.; Pavone, M.; Muñoz-García, A. B.; Kauffmann, B.; Toupance, T.; Chavarot-Kerlidou, M.; Artero, V.; Olivier, C. Design and Synthesis of Novel Organometallic Dyes for NiO Sensitization and Photo-Electrochemical Applications. Dalton Trans. 2016, 45, 12539-12547.

(4) Durand, R. J.; Gauthier, S.; Achelle, S.; Groizard, T.; Kahlal, S.; Saillard, J.-Y.; Barsella, A.; Le Poul, N.; Robin-Le Guen, F. Push-Pull D- $\pi-R u-\pi-A$ Chromophores: Synthesis and Electrochemical, Photophysical and Second-Order Nonlinear Optical Properties. Dalton Trans. 2018, 47, 3965-3975.

(5) Reichardt, C. Solvatochromic Dyes as Solvent Polarity Indicators. Chem. Rev. 1994, 94, 2319-2358.

(6) Campagnola, P. J.; Loew, L. M. Second-Harmonic Imaging Microscopy for Visualizing Biomolecular Arrays in Cells, Tissues and Organisms. Nature Biotechnology 2003, 21, 13561360.

(7) Brédas, J. L.; Adant, C.; Tackx, P.; Persoons, A. Third-Order Nonlinear Optical Response in Organic Materials: Theoretical and Experimental Aspects. Chem. Rev. 1994, 94, 243-278.

(8) Marder, S. R. Organic Nonlinear Optical Materials: where have we been and where are we going? Chem. Commun. 2006, 131-134.

(9) Adamo, C.; Jacquemin, D. The Calculations of Excited-State Properties with TimeDependent Density Functional Theory. Chem. Soc. Rev. 2013, 42, 845-856. 
(10) Dereka, B.; Svechkarev, D.; Rosspeintner, A.; Tromayer, M.; Liska, R.; Mohs, A. M.; Vauthey, E. Direct Observation of a Photochemical Alkyne-Allene Reaction and of a Twisted and Rehybridized Intramolecular Charge-Transfer State in a Donor-Acceptor Dyad. J. Am. Chem. Soc. 2017, 139, 16885-16893.

(11) Orr-Ewing, A. J. Perspective: How can Ultrafast Laser Spectroscopy Inform the Design of New Organic Photoredox Catalysts for Chemical and Materials Synthesis? Struct. Dyn. 2019, 6, 010901-010906.

(12) Biswas, M.; Nguyen, P.; Marder, T. B.; Khundkar, L. R. Unusual Size Dependence of Nonradiative Charge Recombination Rates in Acetylene-Bridged Compounds. J. Phys. Chem. A 1997, 101, 1689-1695.

(13) Nguyen, P.; Lesley, G.; Marder, T. B.; Ledoux, I.; Zyss, J. Second-Order Nonlinear Optical Properties of Push-Pull Bis(phenylethynyl)benzenes and Unsymmetric Platinum Bis(phenylacetylide) Complexes. Chem. Mater. 1997, 9, 406-408.

(14) Lesley, M. J. G.; Woodward, A.; Taylor, N. J.; Marder, T. B.; Cazenobe, I.; Ledoux, I.; Zyss, J.; Thornton, A.; Bruce, D. W.; Kakkar, A. K. Lewis Acidic Borane Adducts of Pyridines and Stilbazoles for Nonlinear Optics. Chem. Mater. 1998, 10, 1355-1365.

(15) Tour, J. M. Molecular Electronics. Synthesis and Testing of Components. Acc. Chem. Res. 2000, 33, 791-803.

(16) Collings, J. C.; Parsons, A. C.; Porres, L.; Beeby, A.; Batsanov, A. S.; Howard, J. A. K.; Lydon, D. P.; Low, P. J.; Fairlamb, I. J. S.; Marder, T. B. Optical properties of Donor-Acceptor Phenylene-Ethynylene Systems Containing the 6-Methylpyran-2-one Group as an Acceptor. Chem. Commun. 2005, 2666-2668. 
(17) Nguyen, P.; Lesley, G.; Dai, C.; Taylor, N. J.; Marder, T. B.; Chu, V.; Viney, C.; Ledoux, I.; Zyss, J. Well-Defined Conjugated Rigid-Rods as Multifunctional Materials: Linear and Nonlinear Optical Properties and Liquid Crystalline Behavior. In Applications of Organometallic Chemistry in the Preparation and Processing of Advanced Materials; Harrod, J. F., Laine, R. M., Eds., 1995; Vol. 297; pp 333-347.

(18) McGrier, P. L.; Solntsev, K. M.; Zucchero, A. J.; Miranda, O. R.; Rotello, V. M.; Tolbert, L. M.; Bunz, U. H. F. Hydroxydialkylamino Cruciforms: Amphoteric Materials with Unique Photophysical Properties. Chem. Eur. J. 2011, 17, 3112-3119.

(19) Bunz, U. H. F.; K.Seehafer; Bender, M.; Porz, M. Poly(aryleneethynylene)s (PAE) as Paradigmatic Sensor Cores. Chem. Soc. Rev. 2015, 44, 4322-4336.

(20) Nojo, W.; Reingold, I. D.; Bard, J. P.; Chase, D. T.; Deng, C.-L.; Haley, M. M. Donor/Acceptor-Substituted Tetrakis(arylethynyl) Benzenes: The Influence of Donor Group on Optoelectronic Properties. ChemPlusChem 2019, 84, 1-6.

(21) Beeby, A.; Findlay, K. S.; Low, P. J.; Marder, T. B.; Matousek, P.; Parker, A. W.; Rutter, S. R.; Towrie, M. Studies of the S1 State in a Prototypical Molecular Wire using Picosecond Time-Resolved Spectroscopies. Chem. Commun. 2003, 2406-2407.

(22) Delor, M.; Keane, T.; Scattergood, P. A.; Sazanovich, I. V.; Greetham, G. M.; Towrie, M.; Meijer, A. J. H. M.; Weinstein, J. A. On the Mechanism of Vibrational Control of Light-Induced Charge Transfer in Donor-Bridge-Acceptor assemblies. Nature Chem. 2015, 7, 689-695.

(23) Wu, Y.; Yu, P.; Chen, Y.; Zhao, J.; Liu, H.; Li, Y.; Wang, J. Intensified CC Stretching Vibrator and Its Potential Role in Monitoring Ultrafast Energy Transfer in 2D Carbon Material by Nonlinear Vibrational Spectroscopy. J. Phys. Chem. Lett. 2019, 10, 1402-1410. 
(24) Bellamy, L. J. The infrared spectra of complex molecules; Methuen \& Co. Ltd: London, 1955.

(25) Tian, D.; Jin, B. FT-IR Spectroelectrochemical Study of the Reduction of 1,4Dinitrobenzene on $\mathrm{Au}$ Electrode: Hydrogen Bonding and Protonation in Proton Donor mixed Media. Electrochim. Acta 2011, 56, 9144-9151.

(26) Ezumi, K.; Miyazaki, H.; Kubota, T. Stretching Vibration of Nitro and N-Oxide Groups of the Anion Radicals of 4-Nitropyridine N-Oxide and Related Nitro Compounds. J. Phys. Chem. 1970, 74, 2397-2402.

(27) Ma, R.; Yuan, D.; Chen, M.; Zhou, M. Infrared Spectrum of Nitrobenzene Anion in Solid Argon. J. Phys. Chem. A 2009, 113, 1250-1254.

(28) Steill, J. D.; Oomens, J. Spectroscopically resolved Competition between Dissociation and Detachment from Nitrobenzene Radical Anion. Int. J. Mass Spectro. 2011, 308, 239-252.

(29) Some confusion exist about the redox-induced shifts of the $r(\mathrm{~N}=\mathrm{O})_{\text {sym }}$ mode reported in the extant literature for nitroaromatics ${ }^{26}$ because the $v(\mathrm{~N}=\mathrm{O})$ modes and the $v(\mathrm{C}-\mathrm{N})$ mode move in opposite directions on the wavelength scale and change intensities, the $\mathrm{v}(\mathrm{N}=\mathrm{O})_{\mathrm{sym}}$ mode crossing the $v(\mathrm{C}-\mathrm{N})$ mode.

(30) Mitzel, F.; Boudon, C.; Gisselbrecht, J.-P.; P. Seiler; Gross, M.; Diederich, F. DonorSubstituted Perethynylated Dehydroannulenes and Radiaannulenes: Acetylenic Carbon Sheets featuring Intense Intramolecular Charge Transfer. Helv. Chim. Acta 2004, 87, 1130-1157.

(31) Walters, K. A.; Kim, Y.-J.; Hupp, J. T. Experimental Studies of Light-Induced Charge Transfer and Charge Redistribution in $\left(\mathrm{X}_{2}\right.$-bipyridine $) \mathrm{Re}(\mathrm{CO})_{3} \mathrm{Cl}$ Complexes. Inorg. Chem. 2002, 41, 2909-2919. 
(32) Frisch, M. J.; Trucks, G. W.; Schlegel, H. B.; Scuseria, G. E.; Robb, M. A.; Cheeseman, J. R.; Scalmani, G.; Barone, V.; Mennucci, B.; Petersson, G. A. et al. Gaussian 09, Revision D.01; Gaussian, Inc.: Pittsburgh, PA, 2015.

(33) Adamo, C.; Barone, V. Exchange Functionals with Improved Long-Range Behavior and Adiabatic Connection Methods without Adjustable Parameters: the mPW and mPW1PW Models. J. Chem. Phys. 1998, 108, 664-675.

(34) Tomasi, J.; Mennucci, B.; Cammi, R. Quantum Mechanical Continuum Solvation Models Chem. Rev. 2005, 105, 2999-3093.

(35) Yanai, T.; Tew, D. P.; Handy, N. C. A New Hybrid Exchange-Correlation Functional using the Coulomb-Attenuating Method (CAM-B3LYP). Chem. Phys. Lett. 2004, 393, 51-57.

(36) Dennington, R.; Keith, T.; Millam, J. GaussView, Version5; Semichem Inc.: Shawnee Mission, KS, 2009.

(37) Stiegman, A. E.; Graham, E. M.; Perry, K. J.; Kundkar, L. R.; Cheng, L.-T.; Perry, J. W. The Electronic Structure and Second-Order Nonlinear Optical Properties of Donor-Acceptor Acetylenes: A Detailled Investigation of Structure-Property Relationships. J. Am. Chem. Soc. 1991, $113,7658-7666$.

(38) Ramakrishna, G.; Bhaskar, A.; T. Goodson, I. Ultrafast Excited State Relaxation Dynamics of Branched Donor-ð-Acceptor Chromophore: Evidence of a Charge-Delocalized State. J. Phys. Chem. B 2006, 110, 20872-20878.

(39) The use of the CAM-B3LYP functional, in principle better suited to model long range charge transfers, ${ }^{9}$ proved unsatisfactory here (Table S2). 
(40) Beeby, A.; Finlay, K.; Low, P. J.; Marder, T. B. A Re-Evaluation of the Photophysical Properties of 1,4-Bis(phenylethynyl)benzene: a Model for Poly(phenyleneethynylene). J. Am. Chem. Soc. 2002, 124, 8280-8284.

(41) A barrier of rotation of $1.7 \mathrm{kcal} \mathrm{mol}^{-1}$ can be derived by DFT for the rotation of the aminophenyl part of the molecule in 2`(Figure S11).

(42) Paul, F.; Mevellec, J.-Y.; Lapinte, C. Vibrational Spectroscopic Investigations of Fe(II) and Fe(III) Organoiron sigma-Alkynyl complexes. Solid State Raman and Solution Infrared Intensity Measurements. J. Chem. Soc., Dalton Trans. 2002, 1783-1790.

(43) Calculations on $\mathbf{1}^{`}$ and $\mathbf{2}^{`}$ in the $\mathrm{S}_{1}$ state predict this mode to appear in the range 1390-1430 $\mathrm{cm}^{-1}$ (Table S3).

(44) Kubicki, J.; Zhang, Y. L.; Wang, J.; Luk, H. L.; Peng, H. L.; Vyas, S.; Platz, M. S. Direct Observation of Acyl Azide Excited States and Their Decay Processes by Ultrafast Time Resolved Infrared Spectroscopy. J. Am. Chem. Soc. 2009, 131, 4212-4213.

(45) Rettig, W. Charge Separation in Excited States of Decoupled Systems-TICT Compounds and Implications Regarding the Development of New Laser Dyes and the Primary Process of Vision and Photosynthesis. Angew. Chem. Int. Ed. 1986, 25, 971-988.

(46) Menning, S.; Krämer, M.; Duckworth, A.; Rominger, F.; Beeby, A.; Dreuw, A.; Bunz, U. H. F. Bridged Tolanes: A Twisted Tale. J. Org. Chem. 2014, 79, 6571-6578.

(47) Krämer, M.; Bunz, U. H. F.; Dreuw, A. Comprehensive Look at the Photochemistry of Tolane. J. Phys. Chem. A 2017, 121, 946-953.

(48) Hamm, P.; Ohline, S. M.; Zinth, W. Vibrational Cooling after Ultrafast Photoisomerization of Azobenzene Measured by Femtosecond Infrared Spectroscopy. J. Chem. Phys. 1997, 106, $519-529$. 
(49) Kubicki, J.; Zhang, Y. L.; Xue, J. D.; Luk, H. L.; Platz, M. Ultrafast Time-Resolved Studies of the Photochemistry of Acyl and Sulfonyl Azides. Phys. Chem. Chem. Phys. 2012, 14, 10377-10390.

(50) The shift of the $v(\mathrm{C} \equiv \mathrm{C})$ band upon population of the singlet state in 2 should be treated cautiously, because the DFT calculations on 2` suggest an inversion of intensity between the two $v(\mathrm{C} \equiv \mathrm{C})$ modes in the first singlet state (corresponding to the $\mathrm{CT}$ state). Based on these calculations, both $v(\mathrm{C} \equiv \mathrm{C})$ modes in 2 should experience different, but smaller (40 and $\left.77 \mathrm{~cm}^{-1}\right)$ shifts than the unique $v(\mathrm{C} \equiv \mathrm{C})$ mode in $\mathbf{1}^{\prime}\left(81 \mathrm{~cm}^{-1}\right)$, contrary to the experimental observations on 1 and $2\left(77 \mathrm{~cm}^{-1}\right.$ vs. $\left.88 \mathrm{~cm}^{-1}\right)$. This discrepancy might result from the change in intensity between the two $v(C \equiv C)$ modes in the singlet state, since a shift of $103 \mathrm{~cm}^{-1}$ is derived from computations when only the most intense $v(\mathrm{C} \equiv \mathrm{C})$ mode is considered in the ground and $\mathrm{S}_{1}$ state.

(51) Dehu, C.; Meyers, F.; Brédas, J. L. Donor-acceptor diphenylacetylenes: geometric structure, electronic structure, and second-order nonlinear optical properties. J. Am. Chem. Soc. 1993, $115,6198-6206$.

(52) Paddon-Row, M. N. Orbital Interactions and Long-Range Electron Transfer. Adv. Phys. Org. Chem. 2003, 38, 1-85.

(53) Zweig, A.; Hoffmann, A. K. Chemistry of dianions. Formation and Reactivity of Anionic Species Derived from Tetraphenylbutadiene. J. Am. Chem. Soc. 1962, 84, 3278-3284.

(54) Wang, Z. H.; Pakoulev, A.; Dlott, D. D. Watching Vibrational Energy Transfer in Liquids with Atomic Spatial Resolution. Science 2002, 296, 2201-2203. 


\section{TOC GRAPHICS}

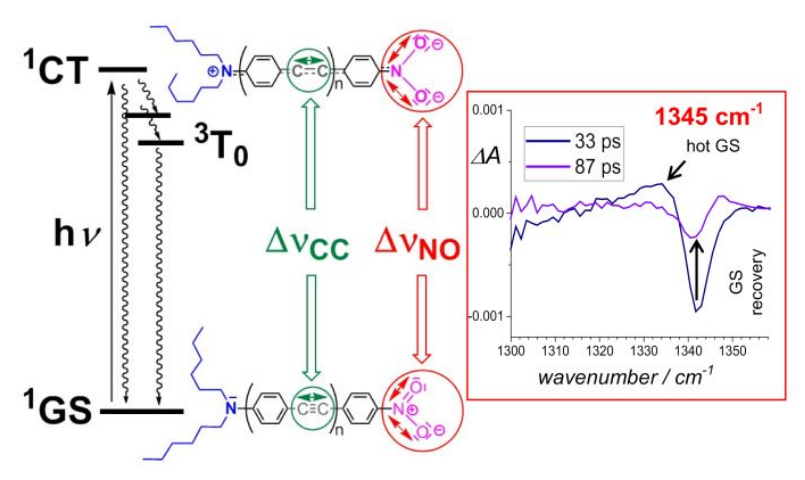

